\title{
Research on Team Building of Private Colleges---Taking the Private Colleges in Shaanxi Province for Example
}

\author{
Du Shixiong \\ Qi Fang Education Research Institute, Xi’an International University, Xi’an, Shaanxi 710077
}

Keywords: Double First-class; private higher education; team building of teachers

\begin{abstract}
Teacher is the key factor that determines the teaching quality, especially in private colleges. However, due to various factors, at present, the team building of teachers in private colleges is still in the developing stage of "cooperating with others", there are many aspects that should be improved such as the teachers' degree, professional title, age, educational background, teaching ability, and the management and team building of the teachers. On the basis of a comprehensive investigation of the present situation of the teachers in a private university in west China, this paper puts forward a lot of suggestions such as setting up post reasonably, increasing investment in scientific research and training, strengthening the cultivation of the reserve teachers, and providing enough guarantees for the development of teachers, so as to promote the team building of private colleges under the background of constructing the "Double First-class" colleges and universities.
\end{abstract}

\section{Introduction}

As a new force of higher education in China, private colleges have played an important role in making up the shortage of national education funds, adjusting the structure of higher education, and realizing the popularization of higher education. However, in recent years, the momentum of rapid development of it has significantly declined ${ }^{[1]}$, the new students are decreasing; the financial resources of the school are becoming increasingly scarce; teaching quality develops slowly, and social reputation increases slowly and tends to decline, etc. In the aspect of teaching quality, the backward teachers' teaching ability and the low level of education management are the persistent diseases in the development of private colleges and universities, which have not been improved any more.

\section{Structure of the Teachers in Private Colleges}

Teachers are the main part of a private college. Whether a college develops well or not, and whether it has developmental potential, all depends on the teachers. For the teachers, the famous Chinese professor Zhou Peiyuan gives his comment that---- "ability of the teachers in a college is the key factor and symbol that determine the college is good or not". This thesis chooses the whole teachers of the second grade in a college as the sample; the sample includes 143 teachers, the specific details as the chart below:

The data above indicate two problems: first, checked the structure of the teachers, we can find out most of the teachers of the private college are the graduates of the domestic universities who have master degree(including the teachers who acquire the master degree after joining the work ) in recent years, the number of these kind of teachers reaches more than $80 \%$, the other part of the teachers is the retired teachers from the public colleges or the teachers who leave the military colleges, most of them was born in 1970s and 1980s, and the nunber of 1980s' is more than one half; second, more than $80 \%$ of the teachers have the professional title of junior grade or medium grade, but, the teachers are 35-55 years old who are usually sophisticated are obviously not enough ${ }^{[2]}$.

Teachers are the supporting force of teaching activities in private colleges, and teaching is a systematic combination of "someone teaching" and "teaching well". So, the team building of the teachers is a kind of human resource project that requires not only quantity, but also quality and 
time. The quantity of the teachers meet the demand of "someone teaching", but in order to achieve "teaching well", the quality of the all teachers must be improved. To improve the teachers' quality, it not only depends on the teachers' educational backgrounds and professional titles, but also depends on the teachers' personal quality and ability, especially the improvement of their personal teaching ability and scienfic reseach ability. At the some time, in order to achieve the improvement, the teachers need to spend time in enriching their experiences, and the accumulation of time determines the age structure of the teachers.

\begin{tabular}{|c|c|c|c|c|c|}
\hline \multirow[t]{3}{*}{$\begin{array}{l}\text { Educational } \\
\text { Background }\end{array}$} & Bachelor & $48(33.6 \%)$ & \multirow[t]{3}{*}{ Age } & $\begin{array}{l}\text { Birth in } \\
1940 s \text { and } \\
1950 s\end{array}$ & $16(11.2 \%)$ \\
\hline & Master & $93(65 \%)$ & & $\begin{array}{l}\text { Birth in } \\
1960 s \text { and } \\
1970 s\end{array}$ & $50(35 \%)$ \\
\hline & Doctor & $2(1.3 \%)$ & & $\begin{array}{l}\text { Birth in } \\
1980 s \text { and } \\
1990 s\end{array}$ & $77(53.8 \%)$ \\
\hline \multirow[t]{3}{*}{ Positional Titles } & $\begin{array}{l}\text { Secondary } \\
\text { senior } \\
\text { positions } \\
\text { and above }\end{array}$ & $26(18.2 \%)$ & \multirow[t]{3}{*}{$\begin{array}{l}\text { Years of } \\
\text { teaching }\end{array}$} & $\begin{array}{l}\text { more than } \\
10 \text { years }\end{array}$ & 106(74.1\%) \\
\hline & lecturer & $94(65.7 \%)$ & & $\begin{array}{l}\text { Less than } \\
10 \text { year }\end{array}$ & $37(25.9 \%)$ \\
\hline & $\begin{array}{l}\text { Junior and } \\
\text { below }\end{array}$ & $18(12.6 \%)$ & & & \\
\hline
\end{tabular}

\section{The Present Situation of Teaching and Scientific Research in Private Colleges}

Teaching, scienfic research and social services are the three elementary functions of the higher education, so are the private colleges. The Deputy Secretary-General of China Association of Higher Education Ye Zhihong said----“"The significance of the Research Report of Private Colleges and Independent Colleges can be summarized as three points: first, it responds to the basic problems of higher education research, and scientific research should also become the center of the development of higher education; the other is to respond to the urgent need to improve the research situation of higher education, and scientific research deficiencies must be made up; third, it responds to the latest problems in the practice of higher education, i.e., while adhering to the principle of supporting education by the government and running schools independently, social forces could take part in the supervision and evaluation of the schools”. Therefore, as an important task of colleges, scientific research not only undertakes the key functions of cultivating the talents, seriveing the society and passing the knowledge on, but also is a important way of developmenting a college and improving the competitive power of a college. By inveestigating the college that the author has mentioned above, the author can not find the satisified data and information. For example, recently, this college has reformed its post setting, and has devided the posts of teachers into 13 levels according to 4 classifications that are Basic, Important, Key, and Crucial. In the 13 leverls, all the levels have not mentioned scientific research except level 1 and level 2. On the teachers' duty, in the Measures for the implementation of the employees, excepting the educational background, it requires the teachers must have the master degree or above, there is only one clause that is----“"the employee must teaching the certain major that is in accord with his or her major". But, how the teachers to teaching the students and if there are some specific demands, the author can not find out from the compilation of rules and regulations of the school. In Measures for the Evaluation of Teacher's Posts of the schools, it makes the request that teachers must publish more that an article in the documents which include SCI, EI, ISTP, SSCI, CSCD, CSSCI, Xinhua Digest, but there is no clear regulation on the workload of scientific research and teachers' teaching activities. 


\section{Management and Excitation for Team Building of the Private Colleges}

Salary incentive is an important way of evaluating teachers' human resource value and teachers' working quality; it has very important functions on dertermining the teachers' job satisfaction, stimulating their work enthusiasms, strengthening the cohesion of teachers and so on. In this study, 200 young and middle-aged teachers in WS College were selected for investigation by means of questionnaire and interview. From the perspective of the salary system, the salaries of the teachers in the school are mainly composed of these items: basic salary, class allowance, and seniority allowance, the college pays the "Five Kinds of Social Insurance and Housing Fund" for the staff according to the $60 \%$ of the average salary of Xi'an city. From the results of the investigation, the income (excluding the wages withheld, same as blow) less than 3,000 yuan accounts for $82.18 \%$, and more than 4,000 yuan only accounts for $6.43 \%$. The salary of the medium staff in management post is much higher than that of the teachers, and the salary of the retired teachers who are employed from the public schools is also relative higer. But even so, the salary of these vice professors and professors is still much less than that of the public schools. In fact, the salary of the teachers in some private colleges is less than half of the corresponding teachers in pulic colleges; they not only earn less salary, but also have less other welfare ${ }^{[3]}$. In aspect of teachers' training and further education, apart from listening to several lectures at the beginning of the new school year, the number of further education for the teachers is very small, and the chances of out studying and inspection belong to the heads of departments, the directors, and the deans.

\section{Suggestions for Improving the Teaching and Managerial Abilities of Private Colleges}

People are the fundamental factor of education, how to make every staff exert their enthusiasms of work to the utmost extent is the problem that must be solved in the transition period of private colleges.

There is a direct relationship between the post setting of private colleges and the position and goals of running schools. How to set proper number of teachers, counselors, administrators and other professional managers must be scientifically investigated and analyzed. According to the statistics reports of the development of higher education in China and the private colleges in Shaanxi Province, the proper ratio of students to teachers is about 15-20: 1.

According to the principles of post establishment of professional and technical post in domestic public colleges and universities, at present, there are four kinds of methods of post establishment: subject method, task method, combination method of subject and task, and structure method ${ }^{[4]}$. According to the actual situation of private colleges, the author thinks teaching, scientific research and social services are the there basic functions of a colleges or university, the teachers of the private colleges must pay attention to scientific research, and teachers in colleges (or higher vocational colleges) must pay attention to social services. So according to the teachers' personal wills, the private colleges could reset the posts of the teachers according to three directions----focusing on teaching, focusing on reseach, and focusing on social services; and then, according to the actual personal working ability, to promote the excellent teachers, at the some time, to support these teachers in the aspects of funds, further education, and salary, so as to excitate the working enthusiasms of the teachers. While for the teachers who does not fulfil the tasks, they would be demoted or paid lower salary, so as to promote all the teachers to try their best to focus on teaching and scientific research.

According to official statistics, the proportion of full-time and part-time teachers in Shaanxi Province reached 1: 1 in 2005, but the structure of the age is obviously unreasonable; there are lots of young teachers who are lack of rich teaching experiences, at the some time, the number of the teachers who will be retired in the near future is also large, but the middle-aged teachers who have enough teaching experiences is rare. Therefore, the leaders of the private colleges should not just focus on the immediate interests, but consider the developmental planning of the colleges for ten years, one hundred years or more, formulate the sustainable talent development strategy for teachers, 
highlight the human resource management to the core position of the school, take people as the centre, and release the teacher's potential to the maximum extent; at the some time, to improve teachers' ability of independent innovation, so as to create the own competitive strength of the private education. Degree, professional titles, including educational background and age, are factors that must be taken into account in the appointment of teachers, but teachers' individual abilities, such as teaching ability, scientific research ability, self-development, and work experience, may be more important to private higher education. Therefore, while considering teachers' own qualities, the external environment that colleges provide for teachers, such as income, teaching environment, scientific research environment, office environment, out training chances, and incentive system, may be more important. We must let teachers in a tolerant, understanding, harmonious cultural atmosphere so that teachers have a true sense of belonging.

Excepting the strategies above, providing the necessary guarantees for the healthy growth of teachers is also the important strategy of the team building of teachers. First, to establish a decision system that is suitable for the development of the private colleges according to the market mechanism and the laws of the operation of the private college. Second, from the perspective of humanism, to provide systemtic guarantees for the development of the teachers; for example, to build the noble sentiment of "Love your work, be grateful and dedication" of the teacher by the excellent Chinese traditional culture, to unite the teachers by good campus culture and so on.

\section{Conclusion}

The "Trinity" of Teaching, Scientific Research and Management are the three elementary factors of a private college's normal operation---- no teaching, no college; no scientific research, no competitive advantage of a college; and no innovative management, all the daily bussiness of a college could be laid aside. But, the staff is the foundamental factor of teaching, scientific research and management. Therefore, The founders of private colleges must know very well about the importance of the team building of the teachers from the perspective of sustainable development of talents, and create all external conditions are conducive to the development of the potential of all kinds of teachers, so that every person who is interested in private education can find a suitable foothold for their own development in the great world of private education, so as to promote the cause of private education to have the next brilliant future.

\section{Acknowledgements}

Pro: Scientific Research Program Funded by Shaanxi Provincial Education Department (Program No.13JZ076)

\section{References}

[1] Wang Qingru, Si Xiaohong. Exploration and Analysis on the "Plateau Phenomenon" in the Development of Private Colleges[J]. Journal of Higher Education, 2011 (11).

[2] Tu Jinye. Problems and Countermeasures on Salary System of the teachers in Private Colleges[J]. Science \& Technology Ecconony Market, 2013(7).

[3] Guo Hong, On the Internal Staff Structure and Post Setting of the Colleges and Universities[J]. Journal of Shenyang Normal University (Social Science Edition), 2007(4). 